\title{
FAMÍlIAS E PATRIARCADO: DA PRESCRIÇÃO NORMATIVA À SUBVERSÃO CRIATIVA
}

\author{
Martha Giudice Narvaz \\ Sílvia Helena Koller \\ Universidade Federal do Rio Grande do Sul
}

RESUMO: Este trabalho problematiza o patriarcado enquanto discurso normativo de papéis familiares, uma vez que valores patriarcais atravessaram os tempos e deixam suas marcas na constituição das famílias ainda na atualidade. A articulação do patriarcado ao capitalismo é também discutida como uma das possíveis explicações para o sistema social de opressão das mulheres. A despeito das conquistas sociais e dos dispositivos legais que postulam a igualdade de direitos entre homens e mulheres, as discriminações ditadas pelo patriarcado são uma forma de violência de gênero e de violação dos direitos humanos das mulheres. Entretanto, apesar da prescrição normativa patriarcal, as famílias inventam outros papéis familiares na cotidianidade de suas experiências, o que explode a hegemonia do discurso patriarcal normativo ainda existente. Isto destaca, ainda, a criativa e subversiva capacidade de resistência humana a prescrições impostas, em especial a resistência das mulheres à opressão patriarcal que lhes tem sido imposta há séculos.

PALAVRAS-CHAVE: famílias; patriarcado; papéis familiares; violência de gênero; direitos das mulheres.

\section{FAMILIES AND PATRIARCHY: FROM NORMATIVE PRESCRIPTION TO CREATIVE SUBVERSION}

ABSTRACT: This paper discusses patriarchy as a normative discourse on family roles, as patriarchal values have crossed centuries and still mark today's family constitution. Patriarchy linked to capitalism is also discussed as one possible explanation for women's oppression in the social system. In spite of social and legal achievements about equality rights between men and women, discrimination established by patriarchy is a kind of gender violence and women's human rights violation. However, despite patriarchy's normative prescription, families invent other family roles in their daily experiences, which explodes the remaining hegemonic patriarchal normative discourse. It also shows the creative and subversive human resistance power against imposed prescriptions, specially female resistance power against patriarchal oppression that has been imposed upon women for centuries.

KEYWORDS: families; patriarchy; family roles; gender violence; women's rights.

Houve um tempo em que não eras uma escrava, lembra-te disso. Caminhavas sozinha, alegre, e banhavas-te com o ventre nu.

Dizes que perdeste toda e qualquer lembrança disso, recorda-te... Dizes que não há palavras para descrevê-lo, dizes que isso não existe. Mas lembra-te. Faze um esforço e recorda-te. Ou, se não o conseguires, inventa.

'Les Guérillères' Monique Witting

Este trabalho problematiza o patriarcado enquanto discurso normativo de papéis familiares. Nosso interesse por este tema construiu-se no trabalho cotidiano com famílias em situação de vulnerabilidade social, em especial com mulheres e crianças marcadas por diversas formas de violação de seus direitos. Nossa inserção em espaços institucionais coletivos enquanto militantes feministas, terapeutas e pesquisadoras conduziu-nos à busca do desvelamento dos discursos produtores de desigualdades e de discriminações inscritas nos contextos familiares e sociais. Nessa trajetória, identificamos que valores patriarcais atravessaram os tempos e deixam suas marcas ainda na atualidade, a despeito das conquistas sociais e dos dispositivos legais que postulam a igualdade de direitos entre homens e mulheres. Tais discriminações são uma forma de violência de gênero e de violação dos direitos humanos das mulheres. Entretanto, apesar da prescrição normativa patriarcal, encontramos famílias que inventam outros papéis familiares e relações na cotidianidade de suas experiências, o que explode a hegemonia do discurso patriarcal normativo ainda existente no imaginário social. Procuramos, ao longo do presente trabalho, destacar a criativa e subversiva capacidade de resistência humana às normatizações reguladoras, em especial a resistência das mulheres à opressão patriarcal que lhes tem sido imposta há séculos.

\section{A invenção da família}

A família não é algo biológico, algo natural ou dado, mas produto de formas históricas de organização entre os humanos. Premidos pelas necessidades materiais de sobre- 
vivência e de reprodução da espécie, os humanos inventaram diferentes formas de relação com a natureza e entre si. As diferentes formas de organização familiar foram, portanto, inventadas ao longo da história. Uma destas formas de organização, centrada na figura masculina, foi a família patriarcal. Houve, e ainda há, outras configurações familiares, entre elas as famílias chefiadas por mulheres, as famílias matrifocais, matrilineares e matrilocais, centradas na figura e na descendência feminina (Narvaz \& Koller, in press).

As organizações humanas nem sempre foram patriarcais. Estudos antropológicos (Engels, 1884/1964; Muraro, 1997) indicam que, no início da história da humanidade, as primeiras sociedades humanas eram coletivistas, tribais, nômades e matrilineares. Tais sociedades (ditas "primitivas") organizavam-se predominantemente em torno da figura da mãe, a partir da descendência feminina, uma vez que desconheciam a participação masculina na reprodução. Os papéis sexuais e sociais de homens e de mulheres não eram definidos de forma rígida e as relações sexuais não eram monogâmicas, tendo sido encontradas tribos nas quais as relações entre homens e mulheres eram bastante igualitárias. Todos os membros envolviam-se com a coleta de frutas e de raízes, alimentos dos quais sobreviviam, bem como a todos cabia o cuidado das crianças do grupo. Muito tempo depois, com a descoberta da agricultura, da caça e do fogo, as comunidades passaram a se fixar em um território. Aos homens (predominantemente) cabia a caça, e às mulheres (também de forma geral, embora não exclusiva), cabia o cultivo da terra e o cuidado das crianças. Uma vez conhecida a participação do homem na reprodução e, mais tarde, estabelecida a propriedade privada, as relações passaram a ser predominantemente monogâmicas, a fim de garantir herança aos filhos legítimos. O corpo e a sexualidade das mulheres passou a ser controlado, instituindo-se então a família monogâmica, a divisão sexual e social do trabalho entre homens e mulheres. Instaura-se, assim, o patriarcado, uma nova ordem social centrada na descendência patrilinear e no controle dos homens sobre as mulheres.

\section{Famílias e patriarcado}

A associação entre famílias e patriarcado remete à origem do termo "família", oriundo do vocábulo latino famulus, que significa "escravo doméstico". Esse novo organismo social - a família - consolidou-se enquanto instituição na Roma Antiga. A família romana era centrada no homem, sendo as mulheres, no geral, meras coadjuvantes. $\mathrm{O}$ patriarca tinha sob seu poder a mulher, os filhos, os escravos e os vassalos, além do direito de vida e de morte sobre todos eles. A autoridade do pater familiae sobre os filhos prevalecia até mesmo sobre a autoridade do Estado e duraria até a morte do patriarca, que poderia, inclusive, transformar seu filho em escravo e vendê-lo (Engels, 1884/1964; Xavier, 1998).
Cabe destacar que o patriarcado não designa o poder do pai, mas o poder dos homens, ou do masculino, enquanto categoria social. O patriarcado é uma forma de organização social na qual as relações são regidas por dois princípios básicos: 1) as mulheres estão hierarquicamente subordinadas aos homens e, 2) os jovens estão hierarquicamente subordinados aos homens mais velhos. A supremacia masculina ditada pelos valores do patriarcado atribuiu um maior valor às atividades masculinas em detrimento das atividades femininas; legitimou o controle da sexualidade, dos corpos e da autonomia femininas; e, estabeleceu papéis sexuais e sociais nos quais o masculino tem vantagens e prerrogativas (Millet, 1970; Scott, 1995).

O patriarcado, enquanto teoria universal e totalizante, é tema controverso no campo dos estudos feministas. Lobo (1992) e Rowbotham (1984) criticam o uso do termo "patriarcado" em função do caráter a-histórico, fixo e determinante impregnado em seu conceito. Castro e Lavinas (1992) ressaltam que o conceito de patriarcado, tomado de Weber, tem delimitações históricas claras, tendo sido utilizado para descrever um tipo de dominação assegurada pela tradição, na qual o senhor é a lei e cujo domínio refere-se a formas sociais simples e a comunidades domésticas. Seria, portanto, inadequado falar, na modernidade, em "sociedade patriarcal". Além disso, na medida em que a família e as relações entre os sexos mudaram, a idéia de patriarcado cristaliza a dominação masculina, pois impossibilita pensar a mudança.

Já para Pateman (1993, p.167), "o poder natural dos homens como indivíduos (sobre as mulheres) abarca todos os aspectos da vida civil. A sociedade civil como um todo é patriarcal. As mulheres estão submetidas aos homens tanto na esfera privada quanto na pública". Nesse sentido, há, segundo ela, um patriarcado moderno, contratual, que estrutura a sociedade civil capitalista. O patriarcado moderno vigente alterou sua configuração, mas manteve as premissas do pensamento patriarcal tradicional. O pensamento patriarcal tradicional envolve as proposições que tomam o poder do pai na família como origem e modelo de todas as relações de poder e autoridade, o que parece ter vigido nas épocas da Idade Média e da modernidade até o século XVII. O discurso ideológico e político que anuncia o declínio do patriarcado, ao final do século XVII, baseia-se na idéia de que não há mais os direitos de um pai sobre as mulheres na sociedade civil. No entanto, uma vez mantido o direito natural conjugal dos homens sobre as mulheres, como se cada homem tivesse o direito natural de poder sobre a esposa, há um patriarcado moderno.

Machado (2000, p.3) admite a existência de um "patriarcado contemporâneo" que foi alterando suas configurações ao longo da história na forma de um patriarcado moderno. Contudo, para esta autora, a diversidade da história ocidental das posições das mulheres, em contextos 
de transformação e de contradições, dificilmente possa ser remetida a uma idéia unitária ou totalizante de patriarcado, a não ser como uma alusão à constante (mas jamais igual) modalidade de dominação masculina.

\section{Patriarcado, capitalismo e violência contra as mulheres}

Ainda que não se possa reduzir ao patriarcado a explicação de todas as formas de desigualdades e de opressão do gênero feminino, devendo ser considerada a articulação do gênero à classe social e às diferentes etnias (Scott, 1995), a gênese da violência contra as mulheres tem sido atribuída predominantemente ao patriarcado em algumas correntes feministas. Embora o patriarcado seja anterior ao advento do capitalismo, estes dois sistemas aparecem articulados na modernidade, duas formas de produzir e de reproduzir a vida a partir de relações de dominação e de expropriação, em especial dos corpos e da autonomia das mulheres (Fonseca, 2000; Saffioti, 1979, 2001; Toledo, 2003). O triunfo do capitalismo, imperial, neoliberal, militarista e depredador revela uma das formas mais elaboradas do patriarcado, que têm mostrado, nos diversos atentados terroristas, nas últimas guerras e na crescente "feminização" da pobreza, sua pior face. Segundo Prá (2001, p.177), “dentre o mais de um bilhão de pessoas da população mundial que se encontra em extrema condição de pobreza, 70\% são mulheres".

As diversas formas de discriminação e de violência contra as mulheres são manifestação de relações de poder historicamente desiguais. Denominadas violência de gếnero, são também violação dos direitos das mulheres. Reconhecidos como parte integral dos direitos humanos pela Conferência Mundial dos Direitos Humanos, da Organização das Nações Unidas (ONU), os direitos humanos das mulheres e das meninas foram, em 1993, pela primeira vez, expressamente concebidos como parte integrante e indivisível dos direitos humanos universais. A violência de gênero - que tem no componente cultural seu grande sustentáculo, fator de produção e de reprodução de violações contra as mulheres - versa no texto da Declaração como incompatível com a dignidade e o valor da pessoa humana (Pandjiarjian, 2003; Saffioti, 2001).

\section{As famílias brasileiras e o patriarcado}

No Brasil, a história da instituição familiar teve como ponto de partida o modelo patriarcal, importado pela colonização e adaptado às condições sociais do Brasil de então, latifundiário e escravagista (Saffioti, 1979; Xavier, 1998). Apesar da desintegração do patriarcado rural, que ocorreu de forma diferenciada em diversas regiões do Brasil, a mentalidade patriarcal permaneceu na vida e na política brasileira através do coronelismo, do clientelismo e do protecionismo (Chauí, 1989). Mesmo no meio urbano, a gênese das atitudes autoritárias sobre a condição feminina deve ser entendida em relação aos esquemas de dominação social que caracterizam o patriarcado tradicional brasileiro (D'Ávila Neto, 1994).

A posição da mulher, na família e na sociedade em geral, desde a colonização até hoje, demonstra que a família patriarcal foi uma das matrizes de nossa organização social. As mulheres brasileiras, nas primeiras décadas do século XX, não haviam conquistado os direitos civis garantidos ao homem. Precisavam exigir seus direitos de cidadã e aumentar sua participação na vida pública. Em 1916, foi criado o Código Civil Brasileiro, patriarcal e paternalista, no qual constava que a mulher casada só poderia trabalhar com a autorização do seu marido. Em 1934, em meio ao governo provisório de Getúlio Vargas, uma nova constituição assegurou o voto da mulher. O trabalho feminino foi regulamentado pela Consolidação das Leis Trabalhistas somente em 1941. Durante a ditadura Vargas, os movimentos feministas foram reprimidos, sendo retomados novamente no início da Segunda Guerra Mundial. Nesta época, nos países desenvolvidos, os homens foram para ofront de batalha e as mulheres tiveram que trabalhar para sustentar suas famílias. O Estado de Bem-Estar Social, característico do pós-Segunda Guerra, em 1945, girava em torno do pleno emprego masculino e propunha o cuidado feminino do lar. A mulher, beneficiária do suporte social assegurado pelo trabalho masculino, não dispunha das mesmas garantias, a não ser enquanto esposa ou filha, o que evidenciava sua condição de dependente do marido/pai. Percebida apenas como uma coadjuvante no sustento da família, não sua mantenedora, o salário feminino poderia ser inferior aos salários gerais. Somente em 1962 é que o Código Civil Brasileiro sofreu alterações, permitindo que mulheres casadas pudessem trabalhar sem a autorização de seus maridos. A Constituição Federal de 1988 e o Novo Código Civil Brasileiro, de 2002, que substituiu o Código Civil, ainda de 1916, consolidaram alguns direitos femininos já existentes na sociedade. No Novo Código, a família não seria mais regida pelo pátrio poder, ou seja, pelo poder do pai, como na época feudal, mas pelo pater familiae, que pressupõe a igualdade de poder entre os membros do casal. Alguns termos que constavam no Código anterior foram alterados a fim de diminuir a linguagem androcêntrica nele contido, entre eles os termos "todo homem", que foi substituído por "toda pessoa". Na Constituição Federal Brasileira, de 1988, marco jurídico-político da transição democrática e da institucionalização dos direitos humanos no país, o princípio constitucional da igualdade entre homens e mulheres está contemplado no art. $5^{\circ}$, que trata dos direitos e garantias fundamentais. $\mathrm{O}$ art. $226, \S 5^{\circ} \mathrm{da}$ Constituição estabelece que "os direitos e deveres referentes à sociedade conjugal são exercidos igualmente pelo homem e pela mulher" (Dias, 2004; Pandjiarjian, 2003; Rocha, 2003). 
Além da referida ordenação jurídica constitucional, o Brasil é signatário junto à ONU de várias convenções que preconizam a eliminação de todas as formas de violência e de discriminação contra as mulheres (Negrão, 2004). Entretanto, a cidadania e a eqüidade, para as mulheres, ainda é ficção. A cidadania formal, estabelecida pela Lei, não garante a cidadania substantiva, ou seja, a capacidade efetiva do exercício dos direitos formais (Prá, 2001). Apesar das conquistas, nas últimas décadas, de vários direitos civis e políticos, as mulheres ainda desconhecem seus direitos (Strey, 2000); seguem acumulando papéis, não contando com uma eqüitativa distribuição de tarefas na esfera doméstica, sendo sobrecarregadas com a dupla jornada de trabalho, com o cuidado da casa e dos filhos (ver Narvaz, 2005).

Estereótipos sexistas, preconceitos e discriminações contra as mulheres ferem o princípio constitucional da isonomia assegurada pela lei e são, portanto, uma forma de violação dos direitos humanos das mulheres. Tais violações ocorrem tanto nas relações familiares e privadas, quanto na esfera pública, nas relações de trabalho e, inclusive, na própria legislação, em especial no que tange aos crimes sexuais e aos ditos "crimes cometidos em defesa da honra masculina" (ver Pandjiarjian, 2003).

\section{Prescrições normativas}

Estudos com famílias brasileiras (Bernardes, 1995; Hileshiem, 2004; Narvaz, 2005; Szymanski, 1997) apontam estereótipos acerca da divisão do trabalho dentro do ambiente doméstico de acordo com o sexo da pessoa e demonstram a tradicional distinção entre os papéis do pai e o da mãe na chamada família nuclear, formada pelos pais e seus filhos dependentes. O papel da mãe ainda remete ao cuidado dos filhos, enquanto o papel do pai, além de prover o sustento, envolve questões de disciplina e de autoridade. A responsabilidade pelas tarefas domésticas e pelo cuidado dos filhos é predominantemente feminina, trabalho (re)produtivo ocultado, negligenciado e desvalorizado pelo contexto social. Embora a participação dos homens nas famílias pobres seja precária, persiste o modelo do homem como provedor financeiro e de autoridade. $O$ papel das mulheres no sustento econômico é invisibilizado e desqualificado, legitimando a crença de que o homem é o legítimo provedor da família, "o que confere uma posição de trabalhadora complementar à mulher, embora os fatos da realidade revelem que as mulheres trabalhadoras muitas vezes são as reais provedoras do sustento familiar" (Fonseca, 2000, p.46).

Se o papel prescrito aos homens na família patriarcal burguesa relaciona-se ao sustento econômico, o papel prescrito às mulheres é o de que sejam cuidadoras do marido, do lar e dos filhos. Essa prescrição parece ter atravessado os séculos, materializando-se na crença de que a mãe deveria dedicar-se integralmente aos filhos, crença encontrada em estudo recente com famílias da periferia de Porto Alegre (Cecconello, 2003). A prescrição de que as mães biológicas criem e cuidem dos(as) filhos(as) é apregoada pelo discurso masculino desde Rousseau, para quem a maternidade é a mais bela função cívica das mulheres. A conseqüente culpabilização da mãe ao afastar-se da prescrição patriarcal contou, desde o Brasil República, com a regulação da medicina higienista, cujo discurso atribuía ao trabalho feminino fora do lar a causa da degradação da família (Rago, 2001). Apesar das evidências empíricas de níveis de bem-estar elevados entre mulheres que possuem um trabalho remunerado (Possati \& Dias, 2002), mitos e crenças que envolveram as conseqüências das atividades remuneradas das mulheres para sua saúde e bem-estar psicológico, legitimaram a teoria de que estas deveriam permanecer em seus papéis tradicionais de mãe e de esposa. $\mathrm{Na}$ atualidade, a mídia também reforça estas informações, gerando culpa para as mulheres que não se limitam à esfera doméstica e aos papéis patriarcais normativos de esposa e mãe dedicadas.

A prescrição patriarcal é regulada por mitos e por discursos (ver Narvaz, 2005) que postulam a maternidade como experiência fundamental ao sentimento de completude das mulheres. A impossibilidade de cumprir adequadamente com o papel materno normativo é vivenciada como incapacidade e com culpa pelas mulheres, o que denuncia as armadilhas do refluxo psicologizante (Keil, 2001), armadilha segundo a qual as mulheres atribuem a si a culpa pela sua condição. Fatores que dificultam o exercício da maternidade, tais como a pobreza e a falta de suporte conjugal, comunitário ou social, em especial às mulheres chefes de família, não remetem à estrutura social desigual e sexista imposta pela ordem capitalista patriarcal. A impossibilidade de cumprir com a "maternidade normativa" é atribuída a uma falha individual, descolada do contexto histórico e social que a produziu. Ao depositarem individualmente na figura da mulher-mãe-trabalhadora a responsabilidade por sua condição de pobreza, de abandono e/ou negligência no cuidado dos filhos e filhas, discursos científicos e sociais isentam os homens, o Estado e a comunidade de sua responsabilidade social (Narvaz, 2005; Silva, 1993; Strey, 2000).

Uma vez que a exclusão da pobreza fragiliza os laços sociais e dificulta o acesso a recursos de apoio social, os benefícios, mesmo que mínimos, da sociedade salarial, (Castel, 1998; Nardi, 2003) e a efetividade de políticas públicas para as mulheres são condição fundamental à superação da sua condição histórica de vulnerabilidade produzida por discriminações. Sabemos que não reside exclusivamente nos fatores econômicos a possibilidade de emancipação feminina, "uma vez que os mesmos são necessários, mas não suficientes para a efetivação das rupturas culturais implícitas à luta das mulheres" (Fonseca, 2000, p.52). No entanto, sem a proteção do Estado de bem-estar social que, no Brasil, sequer de fato existe (Keil, 2001), 
as mulheres permanecem "despossuídas" de direitos e à mercê das desigualdades econômicas e sociais, o que tem sido visto no crescente fenômeno da "feminização" da pobreza (Prà, 2001). Nesse sentido, a proposição de políticas públicas transversais, afirmativas e sensíveis às desigualdades de gênero pode contribuir à garantia de direitos e ao empoderamento (Leon, 2000) das mulheres. Para tanto, há que se dar visibilidade aos mecanismos produtores de desigualdades e de opressão, entre eles o patriarcado, articulado ao capitalismo, nas sociedades contemporâneas.

\section{Subversões criativas}

Apesar das prescrições normativas, as famílias desvelam em seu bojo marcas de subversão e de resistência às normatizações impostas, emergindo daí papéis familiares cotidianamente vividos de forma plural, heterogênea, criativa e subversiva. Estudo recentemente realizado sobre as posições ocupadas por uma mulher diante das violações sofridas por ela e por suas filhas (ver Narvaz, 2005) revelou que, tanto em relação à divisão das tarefas domésticas, quanto ao sustento econômico e ao cuidado dos filhos, a ordem patriarcal, apesar de prescritiva e normativa na estruturação dos papéis e das relações familiares foi, em muitas situações, subvertida. Os homens, percebidos pela participante do estudo, como provedores econômicos, efetivamente não o são, ao menos de forma exclusiva. As mulheres também contribuem com seu trabalho ao sustento econômico da família, ainda que desvalorizem sua capacidade de trabalho. Os homens, mesmo não sendo os principais cuidadores dos filhos, podem ser fonte de apoio, de cuidado e proteção, mesmo de filhos que não são seus (biológicos). As mulheres, às quais são atribuídos os papéis de cuidado do marido, do lar e da prole, também cometem transgressões, abandonam a família, traem os maridos e fogem com amantes, subvertendo, assim, as prescrições de obediência e de submissão das mulheres à figura masculina reguladas pela ordem patriarcal.

\section{Considerações Finais}

Diante do exposto, entendemos que a normatização das relações familiares regulada pelo patriarcado atravessou a história e permanece ainda na atualidade. No entanto, coexistem valores contemporâneos e tradicionais na definição destes papéis (Vaitsman, 1997), bem como há diferentes configurações na constituição das famílias brasileiras alternativas ao modelo burguês, nuclear e patriarcal, tais como as famílias chefiadas por mulheres, as famílias extensas, as famílias de criação (Correa, 1982; Fonseca, 1989, 1997) e os casais e famílias homossexuais (Goodrich, Rampage, Ellman \& Halstead, 1990). Estereótipos sexistas que fundamentam desigualdades de gênero têm sido encontrados em diversas configurações familiares. Sobretudo em famílias marcadas por relações de violência, a hierarquia e a obediência do grupo familiar à figura mas- culina, característicos das organizações patriarcais, são naturalizados e legitimam diversas formas de abusos masculinos, inclusive os sexuais (Narvaz \& Koller, 2004). Uma vez que submissão e resistência sempre fizeram parte da história das mulheres (Strey, 2000), apesar da normatização patriarcal, na cotidianidade vivida, papéis familiares normatizados são também subvertidos.

Homens e mulheres, apesar das normatizações impostas, são capazes de resistência e de subversão, mostrandose plurais e heterogêneos. Tal pluralidade "explode" o discurso patriarcal monolítico normativo, abrindo possibilidades para a subversiva e criativa (re)invenção de papéis e de relações. A mesma sociedade patriarcal e capitalista que normatiza às mulheres o cuidado de seus filhos/as, e aos homens o sustento econômico da família, não lhes dá condições para o desempenho destes papéis. Residam talvez aí possibilidades, mesmo que perversas, de subversão à normatização. Sujeitos e discursos devem ser compreendidos a partir de sua heterogeneidade constitutiva, dispersos em múltiplas, criativas, contraditórias e subversivas possibilidades inscritas em determinado tempo e espaço históricosocial (Pêcheux, 1969/1983; Scott, 1995).

É preciso revisar a idéia hegemônica de família e de papéis familiares, dado que o estigma atribuído aos sujeitos que vivem configurações e papéis alternativos aos normativos é opressivo, fonte de sofrimento psíquico $(\mathrm{Ca}-$ nevacci, 1987; Figueira, 1986) e terreno fértil para desigualdades e violações (ver Narvaz \& Koller, in press). Ao deslocar o olhar das concepções homogêneas de papéis familiares para as possibilidades de resistência dos sujeitos às normatizações impostas, não deve, entretanto, ser desconsiderada a vigência do patriarcado enquanto discurso normativo ainda na atualidade. A despeito das conquistas sociais e legais das mulheres, papéis e relações assentados em discriminações e desigualdades de gênero permanecem neste novo século e invadem as ciências, as artes, a política; invadem, enfim, a cotidianidade de nossas vidas.

\section{Referências}

Bernardes, N.M.G. (1995). Ser mulher, ser homem: significações construídas por crianças de classes populares. In: Jacques, M.G.C.(Ed.), Relações sociais e ética (pp.219-232). Porto Alegre: ABRAPSO.

CanevacciI, M. (1987). Dialética da família. Gênese, estrutura e dinâmica de uma instituição repressiva. São Paulo: Brasiliense.

Castel, R. (1998). As metamorfoses da questão social: uma crônica do salário. Petrópolis: Vozes.

Castro, M. \& Lavinas, L. (1992). Do feminino ao gênero: a construção de um objeto. In: Costa, A. \& Bruschini, C. (Eds.),Uma questão de gênero (pp.216-251). São Paulo: Rosa dos Tempos.

Cecconello, A.M. (2003). Resiliência e vulnerabilidade em famílias em situação de risco. Tese de Doutorado em Psicologia do Desenvolvimento, Universidade Federal do Rio Grande do Sul. Porto Alegre, RS.

Chaú, M. (1989). Conformismo e resistência: aspectos da cultura popular no Brasil (4 $4^{a}$.ed.). São Paulo: Brasiliense. 
Corrêa, M. (1982). Colcha de Retalhos: estudos sobre a família no Brasil. São Paulo: Brasiliense.

D’Ávila Neto, M.I. (1994). O autoritarismo e a mulher: o jogo da dominação macho-fêmea no Brasil. Rio de Janeiro: Artes \& Contos.

Dias, M.B. (2004). Conversando sobre a mulher e seus direitos. Porto Alegre: Livraria do Advogado.

Engels, F. (1884). El origem de la familia, de la propiedad privada e del Estado. Buenos Aires: Clariedad (Original publicado em 1884).

Figueira, S. (1986). Uma nova família? Rio de Janeiro: Zahar, 1986.

Fonseca, C. (1989). Pais e filhos na família popular. In: D’Incao, M.A. (Ed.) Amor e família no Brasil (pp.95-128). São Paulo: Contexto.

Fonseca, C. (1995). Caminhos da adoção. São Paulo: Cortez.

Fonseca, C. (1997). Ser mulher, mãe e pobre. In: Del Priore, M. (Ed.), História das mulheres do Brasil (pp.510-533). São Paulo: Contexto.

Fonseca, T.M.G. (2000). Gênero, subjetividade e trabalho. Petrópolis: Vozes.

Goodrich, T.J., Rampage, C., Ellman, B. \& Halstead, K. Terapia feminista da família. Porto Alegre: ArtMed.

Hileshiem, B. (2004). Trabalho doméstico: "O serviço de sempre". In: Strey, M.N., Cabeda, S.T.L. \&. Prehn, D.R (Eds.) Gênero e Cultura: questões contemporâneas (pp.39-52). Porto Alegre: EDIPUCRS.

Keil, I.M. (2001). Capitalismo, ordem social e exclusão: por uma discussão de teorias. In: Baquero, M. (Ed.) Reinventando a sociedade na América latina: cultura política, gênero, exclusão e capital social (pp.71-115). Porto Alegre: UFRGS.

Leon, M. (2000). Empoderamiento: Relaciones de las mujeres con el poder. Estudos Feministas, 8, 191-207.

Lerner, G. (1989). The creation of patriarchy. New York: Oxford.

Lobo, E. (1992). O trabalho como linguagem: o gênero do trabalho. In: Costa, A. \& Bruschini, C. (Eds.) Uma questão de gênero (pp.252-265). Rio de Janeiro: Rosa dos Tempos.

Machado, L.Z. (2000). Perspectivas em confronto: relações de gênero ou patriarcado contemporâneo? In: Sociedade Brasileira de Sociologia (Ed.) Simpósio Relações de Gênero ou Patriarcado Contemporâneo, 52 $2^{\mathrm{a}}$ Reunião Brasileira para o Progresso da Ciência. Brasília: SBP.

Millet, K. (1970). Sexual politics. New York: Doubleday \& Company.

Muraro, R.M. (1997). A mulher no terceiro milênio: uma história da mulher através dos tempos e suas perspectivas para o futuro ( $4^{\mathrm{a}}$. ed.). Rio de Janeiro: Record, Rosa dos Tempos.

Nardi, H.C. (2003). A propriedade social como suporte da existência: a crise do individualismo moderno e os modos de subjetivação contemporâneos. Psicologia \& Sociedade, 1(15), 37-56.

Narvaz, M. (2005). Submissão e resistência: explodindo o discurso patriarcal da dominação feminina. Dissertação de Mestrado nãopublicada, Programa de Pós-graduação em Psicologia do Desenvolvimento, Universidade Federal do Rio Grande do Sul. Porto Alegre, RS.

Narvaz, M. \& Koller, S.H. (2004). Famílias, violências e gêneros: desvelando as tramas da transmissão transgeracional da violência de gênero. In: Strey, M.N., Azambuja, M.P.R. \& Jaeger, F.P. (Eds.) Violência, gênero e políticas públicas (pp.149-176). Porto Alegre: EDIPUCRS.

Narvaz, M. \& Koller, S.H. (in press). A concepção de família de uma mulher-mãe de vítimas de incesto. Psicologia, Reflexão \& Crítica.

Negrão, T. (2004). Nós e rupturas da rede de apoio às mulheres. In: Strey, M.N., Azambuja, M.P.R. \& Jaeger, F.P. (Eds.) Violência, gênero e políticas públicas (pp.215-258). PortoAlegre: EDIPUCRS.

Pandjiarjian, V. (2003). Os estereótipos de gênero nos processos judiciais e a violência contra a mulher na legislação. Disponível em: www.cladem.org/htm. Acesso em: 08/0/2004.

Pateman, C. (1993). O contrato sexual. Rio: Paz e Terra.

Pêcheux, M. (1969). A análise automática do discurso. In: Gadet, F. \& Hak, T. (Eds.), Por uma análise automática do discurso: uma introdução à obra de Michel Pêcheux (pp.32-47). Campinas: UNICAMP (Original publicado em 1969).

Possati, I.C. \& Dias, M.R. (2002). Multiplicidade de papéis da mulher e seus efeitos para o bem-estar psicológico. Psicologia: Reflexão \& Crítica, 15, 293-301.

Prá, J.R. (2001). Cidadania de gênero, capital social, empoderamento e políticas públicas no Brasil. In: Baquero, M. (Ed.) Reinventando a sociedade na América latina: cultura política, gênero, exclusão e capital social (pp.173-208). Porto Alegre: UFRGS.

Rago, M. (2001). Trabalho feminino e sexualidade. In: Del Priore, M. (Ed.) História das mulheres do Brasil. (2a . ed., 578-606). São Paulo: Contexto.

Rocha, J.C. (2003). Mulher, família e trabalho numa abordagem sócio-histórica. Monografia não publicada, Curso de Formação de Psicólogos, Universidade Estácio de Sá. Rio de Janeiro, RJ.

Rowbotham, S. (1984). Lo malo del patriarcado. In: Samuel, R. (Ed.) Historia popular y teoria socialista (pp.248-256). Barcelona: Crítica.

Saffioti, H. (1979). A mulher na sociedade de classes: mitos e realidade. Rio de Janeiro: Rocco.

Saffioti, H. (2001). Contribuições feministas para o estudo da violência de gênero. Cadernos Pagu, 16, 115-136.

Scott, J. (1995). Gênero: uma categoria útil de análise histórica. Educação \& Realidade, 20, 71-99.

Silva, R.S. (1993). Cegonhas indesejadas: aborto provocado. Estudos Feministas, 1, 123-134.

Strey, M. N. (2000). Será o século XXI o século das mulheres? In: Strey, M.N., Mattos, F., Fensterseifer, G. \& Werba, G.C. (Eds.) Construções e perspectivas em gênero (pp.9-18). São Leopoldo: Unisinos.

Szymanski, H. (1997). Teorias e "teorias" de famílias. In: Carvalho, M.C.B. (Ed.) A família contemporânea em debate (pp.23-27). São Paulo: EDUC.

Toledo, C. (2003). Mulheres: o gênero nos une, a classe nos divide ( $2^{a}$. ed., Série Marxismo e opressão). São Paulo: José Luís e Rosa Sundermann.

Vaitsman, J. (1997). Pluralidade de mundos entre mulheres de baixa renda. Estudos Feministas, 2, 303-319.

Xavier, E. (1998). Declínio do patriarcado: a família no imaginário feminino. Rio de Janeiro: Record, Rosa dos Tempos. 
Martha Giudice Narvaz é Psicóloga, Terapeuta Familiar e Militante Feminista, Doutoranda em Psicologia do Desenvolvimento pela Universidade Federal do Rio Grande do Sul. phoenx@terra.com.br

Sílvia Helena Koller é Psicóloga, Professora do Programa de Pós-Graduação em Psicologia do Desenvolvimento da Universidade Federal do Rio Grande do Sul. Coordenadora do Centro de Estudos Psicológicos sobre Meninos e Meninas de Rua-CEPRUA/UFRGS. Endereço: Rua Ramiro Barcelos, 2600, 104, 90035 003, Porto Alegre, RS, Brasil.

skoller@uol.com.br

Este artigo foi realizado com base na Dissertação de Mestrado da primeira autora sob a orientação da segunda autora.

\section{Agradecimentos}

Às alunas do Curso de Graduação de Psicologia da UFGRS que integraram nossa equipe de pesquisa, Júlia Bongiovani e Lívia Zanchet; Ao Prof. Dr. Henrique Caetano Nardi, do Programa de Pós-Graduação em Psicologia Social e Institucional do Instituto de Psicologia da UFGRS, por suas contribuições à discussão da questão da exclusão social;

Ao Cnpq pelo apoio durante a realização do estudo a partir do qual foi escrito este texto.

Famílias e patriarcado: da prescrição normativa à subversão criativa

Martha Giudice Narvaz e Sílvia Helena Koller

Recebido: 28/02/2005

$1^{\mathrm{a}}$ revisão: $7 / 06 / 2005$

$2^{\mathrm{a}}$ revisão: $5 / 09 / 2005$

$3^{\mathrm{a}}$ revisão: $13 / 12 / 2005$

Aceite final: 16/02/2006 